\title{
Features of Weediness of the Field by Root Residues of Corn
}

\author{
Mykola Korchak \\ Faculty of Engineering and \\ Technology \\ State Agrarian and Engineering \\ University in Podilia, \\ Kamianets-Podilskyi, Ukraine \\ korchak_nikolay@ukr.net \\ Lesya Burko \\ Agrobiological Faculty, \\ National University of Life and \\ Environmental Sciences of Ukraine, \\ Kyiv, Ukraine
}

\author{
Serhii Yermakov \\ Educational and Scientific \\ Laboratory "DAK GPS", \\ State Agrarian and Engineering \\ University in Podilia, \\ Kamianets-Podilskyi, Ukraine \\ dakgps@pdatu.edu.ua \\ Weronika Tulej \\ Institute of Mechanical Engineering \\ Warsaw University of Life Sciences - \\ SGGW \\ Warsaw, Poland
}

\author{
Taras Hutsol \\ Institute of Energy, \\ State Agrarian and Engineering \\ University in Podilia, \\ Kamianets-Podilskyi, Ukraine \\ pro-gp@pdatu.edu.ua
}

\begin{abstract}
The presence of a large amount of root residues after harvesting corn creates problems for the processing of the field. On the basis of field and laboratory studies, the character of weediness and the main physical and morphological characteristics of rhizomes were revealed. Analysis of the variation curves of the dimensional characteristics of root residues and the mass graphical dependences of rhizomes made it possible to develop a general approach to freeing fields from plant residues of corn.
\end{abstract}

Keywords - weediness of the field, root residues, corn, ground part, rhizome.

\section{INTRODUCTION}

The existing knowledge regarding the use of plant residues of maize for energy purpose gives reason to determine the urgent tasks of research on this problem. The main ones are:

- development of a yearbook for the study of the nature of weediness of the field by plant residues of corn and methods for processing experimental data;

- development of methods for the efficient use of plant residues in energy production;

- the development of field processing methods after harvesting corn and other thick-stemmed crops;

- development and creation of appropriate agricultural machinery.
Common shortcomings in the work of research institutions conducting research on the effective use of plant residues are insufficiently comprehensive research, as well as, insufficient effectiveness of coordination of scientific work.

The capacity of the corn root system largely depends on the nature of the soil and its moisture: on loosened and moderately moist soils the root system develops better than on dense and very moist, as well as excessively dry soils.

Scientific research is devoted to processing problems $[3,4]$. They have proposed a mechanized technology the essence of which lies in multi-pass disking in different directions with heavy disk tools.

Milling solid is considered more efficient [5,6]. Scientists of NRC (National Research Center) "Institute for Mechanization and Electrification of agriculture" (settlement of town type Glevakha) after to pre-crush surface leaf and stem mass by forager drums.

The only rational recommended mechanized technology of grinding leaf-stem and root mass before the tillage of the soil is absent in Ukraine. Therefore there is an acute production problem that requires a scientific and applied solution.

In solving this problem at the first stage, we see the classical scheme, namely: 
- study of the processing object;

- analysis of existing methods and studies of studying the contamination of the field by root residues;

- - conducting research on fixing the quantitative and qualitative characteristics of rhizomes and ground parts of corn;

- - data processing and search for solutions to free the field from corn residues.

Some studies of the state of weediness of the field after harvesting corn were considered by the authors earlier [7-9].

The main purpose of field contamination is: a study of the processing object of root residues as elements that need to be crushed in time and embedded into the soil.

The list of issues under study includes: determination of the dimensional characteristics of rhizomes and ground parts, study of corn rhizomes to determine the location of their bulk and the required depth of processing.

The results obtained will be the basis for further engineering decisions for developing machine designs, selecting a technological scheme; determining technological parameters.

\section{MATERIALS AND METHODS}

To find ways and means of solving this problem you should carefully examine the state of the field.

Stubble after corn harvesting was chosen as the field littered by root residues of thick-stem crops.

The technique of conducting research into the nature of the field contamination by root residues of corn is shown in Figure 1.

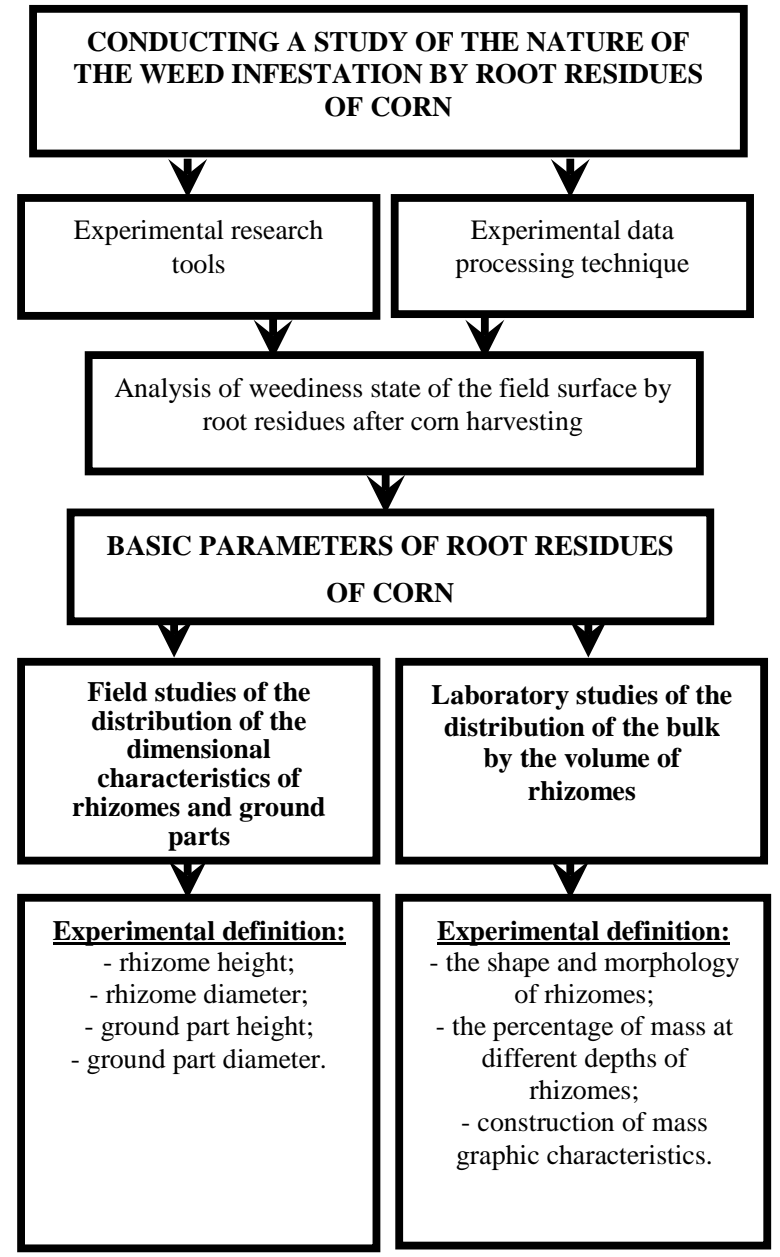

Fig. 1. Methods of researching the nature of the field contamination by root residues of corn

Experimentaly there were determined (Figure 2):

1. Plant residues diameters:

- rhizomes diameters $d_{k}$;

- ground parts diameters $d_{H}$;

2. Plant residues height:

- rhizomes height (provisionally) $h_{k}$;

- ground parts height (provisionally) $h_{H}$.
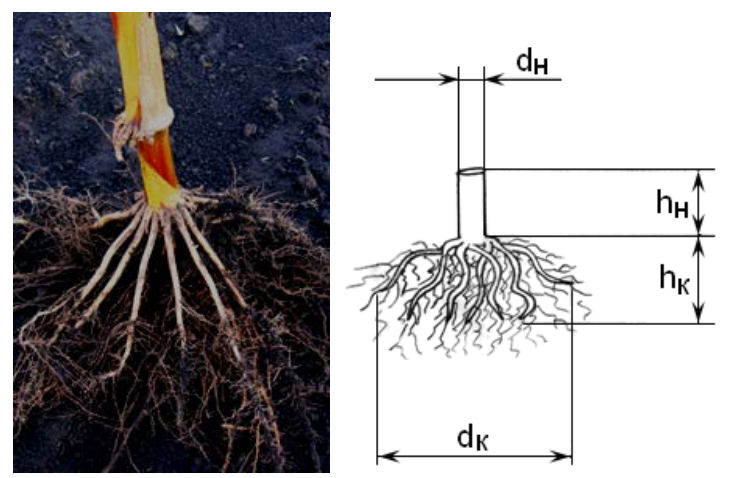

Fig. 2. Measurements scheme rhizomes: $\mathrm{d} \kappa-$ rhizome diameter, $\mathrm{dH}-$ ground part diameter, hk - rhizome height; hg - ground part height. 
Environment. Technology. Resources. Rezekne, Latvia Proceedings of the $13^{\text {th }}$ International Scientific and Practical Conference. Volume 1, 122-126

Planning tests and processing the results obtained was carried out according to the existing techniques of field and engineering experiments [8]. Measurement variability of the object studied was determined by variant rows and variant curves.

\section{RESULTS AND DISCUSSION}

Useful experimental studies of the weediness of the field by root residues of thick-stem crops were carried out on the experimental field of Podolsky state agrarian and technological university.

Soil type - chernozem (black earth zone) ordinary, slightly humus. Background - stubble after corn harvesting.

Processing the experimental data according to the method described above, a series of variation curves was obtained from which above given parameters were calculated.

The research results are as follows:

a) Results of the distribution of dimensional characteristics of rhizomes and ground parts.

- Characteristics of the height and diameter of the rhizome (Fig. 3).

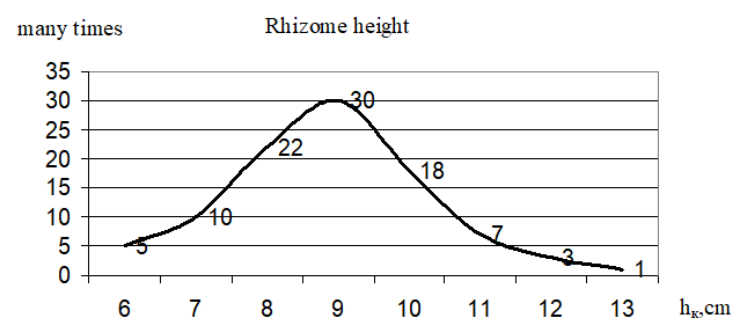

a)

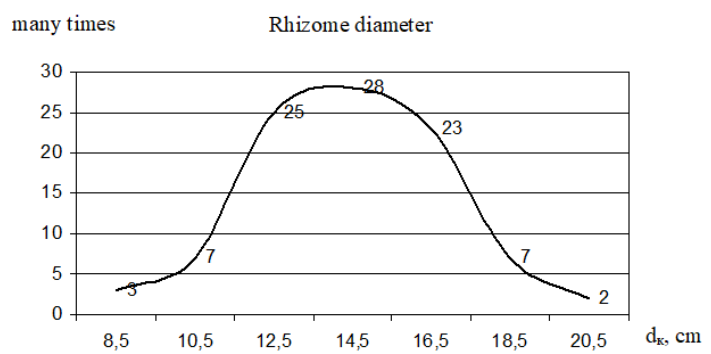

b)

Fig. 3. Research results: a) rhizome height $(\mathrm{Mc}=8,9 \mathrm{~cm} ; \sigma=1,4$ $\mathrm{cm})$; b) rhizome diameter $(\mathrm{Mc}=14,4 \mathrm{~cm} ; \sigma=2,5 \mathrm{~cm})$ $d_{\kappa} \min$.

Examining the research data found: $h_{\kappa \max }, h_{\kappa \min }, d_{\kappa \max }$,

$h_{\text {max }}=13 \mathrm{~cm}, h_{\text {min }}=6 \mathrm{~cm}, d_{\text {max }}=20 \mathrm{~cm}, d_{\text {min }}=8,5 \mathrm{~cm}$.

- Characteristic of the height and diameter of the ground part (Fig.4).

When examining research data there were found: $h_{\text {н.ч. }}$ $\max , h_{\text {H.ч. } \min }, d_{\text {H.ч. } \max }, d_{\text {H.ч. } \min .}$ $h_{\text {н.ч. } \max }=24 \mathrm{~cm}, h_{\text {н.ч. } \min }=6 \mathrm{~cm}, d_{\text {H.ч. } \max }=24 \mathrm{~mm}, d_{\text {H.ч. }}$ $\min =11 \mathrm{~mm}$.

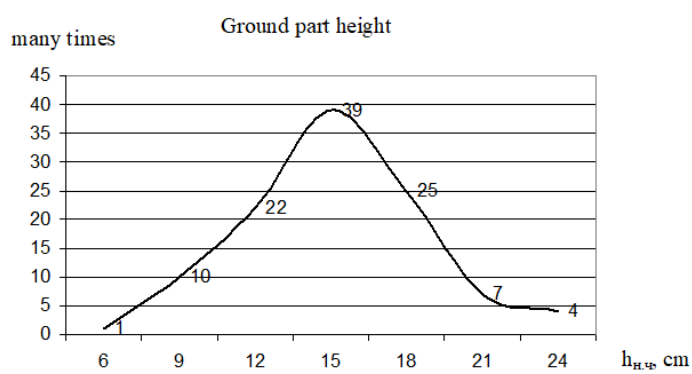

a)

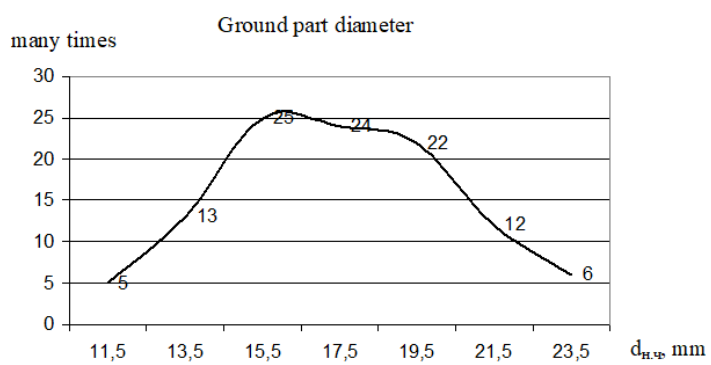

b)

Fig. 4. Figure 4. Research results: a) ground part height $(\mathrm{Mc}=15,2$ $\mathrm{cm} ; \sigma=3,7 \mathrm{~cm}) ; \mathrm{b})$ ground part diameter $(\mathrm{Mc}=17,5 \mathrm{~mm} ; \sigma=3,0$ $\mathrm{mm}$ )

b) Research of maize rhizomes to determine their main mass location and the required depth of cultivation was carried out in laboratory conditions on samples taken on separate experimental plots.

Calculations were carried out according to the formula:

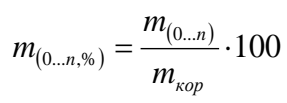

where $\left(m_{0 . . n n}, \%\right)$ - the percentage of mass at a depth of 0 to $n \mathrm{~cm}, \%$;

$m_{(0 . . n)}$ - rhizomes mass for each centimeter from 0 to $n$ cm, g;

$m_{\text {tot }}-$ total mass of a rhizome, g.

The results of calculations are shown in Fig. 5. 1-st sample

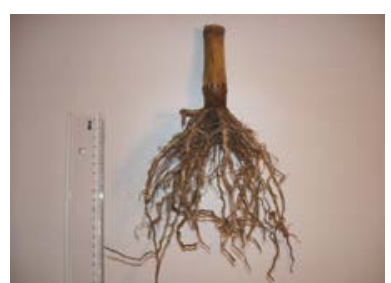

Rhizome mass $\mathrm{m}_{\text {кор }}=42$ gr. 2-nd sample

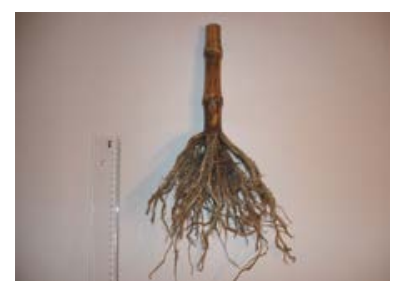

Rhizome mass $\mathrm{m}_{\text {кор }}=38$ gr. 


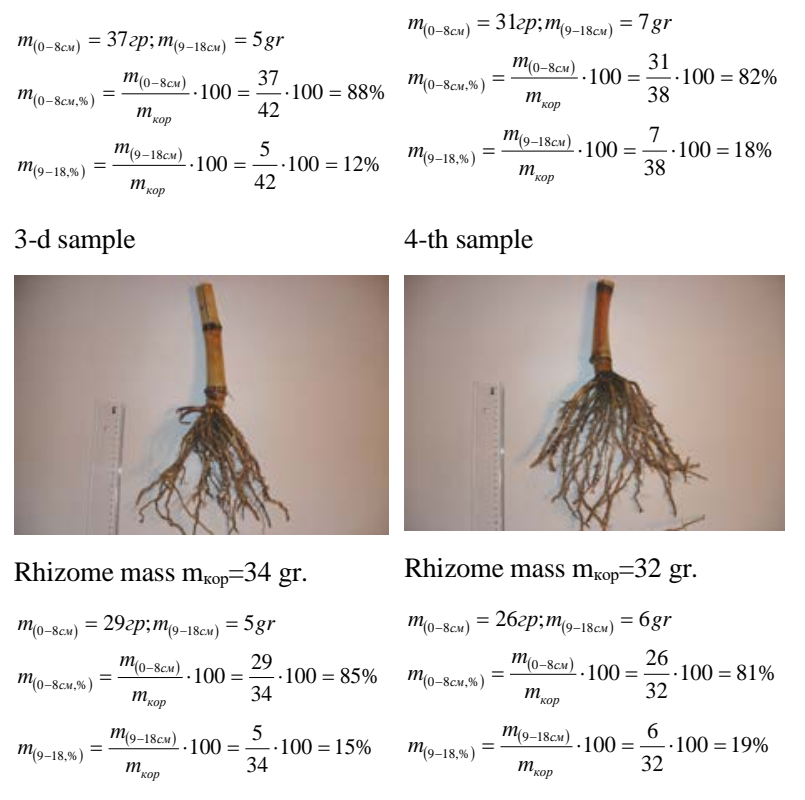

Fig. 5. Corn rhizomes during research in the laboratory

After calculations a mass diagram was constructed for each centimeter of rhizomes distribution (Fig. 6).

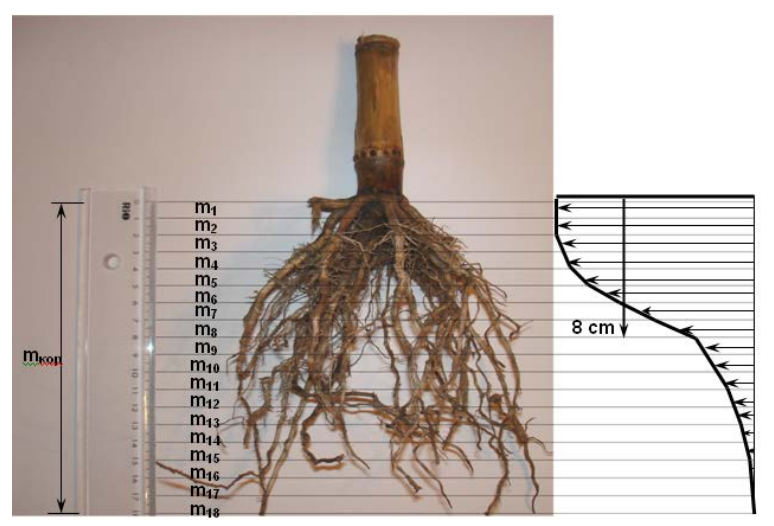

a)

b)

Fig. 6. Study of corn rhizomes to determine the location of the main mass and the required processing depth: $\mathrm{a}$ - rhizome, $\mathrm{b}-\mathrm{a}$ mass diagram

Experimental data of rhizomes showed that the bulk of the roots is at a depth of $8 \mathrm{~cm}$. So, the depth of processing when conducting useful research is chosen in the range from 2 to $8 \mathrm{~cm}$.

On the basis of studies of the state of contamination a method has been developed for cultivation a field clogged with plant residues of thick-stem crops and shredder for its implementation [10-15]. The novelty of technical decisions was confirmed by patens of Ukrainian invention $[16,17]$.

\section{CONCLUSIONS}

As a result of the research conducted on the state of the field weediness by rhizomes and their ground part the following was revealed:
- the variance or standard deviation of all measurements is quite significant that is significant variation of parameters (within $\mathrm{M}=3 \pm \sigma$ );

- the medium-arithmetic development of height of the rooster (rhizome) $\mathrm{M}_{\mathrm{c}}=8,9 \mathrm{~cm}$ with with variation curve is visible that the basic part of the heights lies in the limits of $7,5-10 \mathrm{~cm}$. This indicates that for treatment (cultivation) of the rooting system considering the degree of crushing, it is enough to enhance the working body in $8 . . .9 \mathrm{~cm}$;

- average arithmetic deviation of the diameter of the rhizome $\mathrm{M}_{\mathrm{c}}=14,4 \mathrm{~cm}$, and the main part of measurements lies within 12,5...18,5 cm; therefore the required row cultivation width is at least $20 \mathrm{~cm}$;

- diameter of the ground part varies widely the main part of measurements is $15 \ldots 20 \mathrm{~cm}$ and reaches a maximum of $24 \mathrm{~cm}$. This should be considered when choosing the method of grinding and the working body;

- the average value of the height of the ground part (cutting height) is 15,2cm which meets the agrotechnical requirements of corn harvesting.

2. Considering the obtained statistical quantitative data of debris and their quantitative characteristics:

- the presence of a large amount of crop residues makes it difficult to cultivate the soil and worsen the further use of the field which requires carrying out operations to free the fields from coarse plant residues, more over, given the fibrous structure of corn stalks, it can be concluded that for grinding the corn crop residues it is necessary to use working bodies that cut rather than break the stems, provide a sufficient degree of grinding, good sealing and mixing with the soil.

- processing to free the field from root residues, as noted above, must be carried out to the depth of the main roots. Since the energy consumption of the process is directly proportional to the processing depth, the processing depth must be taken within $7 . . .9 \mathrm{~cm}$.

\section{REFERENCES}

[1] Boyko P.I. Corn (Maize) in intensive crop rotation. Kyiv: Urozhay, 1990.

[2] Godulyan I.S. Maize in crop rotations. Kyiv: Urozhay, 1977.

[3] Godulyan I.S. Rational crop rotations - basis of high yield. Dnepropetrovsk: Promin', 1972.

[4] Ilchenko V.Yu., Nagirny Yu.P. Machine use in agriculture Kyiv: Urozhay, 1996.

[5] Lystopad G.E., Demidov G.K. and Zonov B.D. Agricultural and land reclamation machines. Moskow: Kolos, 1976.

[6] Korchak M.M. and Yermakov S.V. "Study of the nature of the field weediness with leafy and root residues after harvesting corn". Collection of scientific papers of the Podolsky State Agrarian and Technological University. Kamenets-Podolsky, 2007. pp. 498 - 504.

[7] Korchak M., Yermakov S. and Maisus V., Eds. "Problems of field contamination when growing energy corn as monoculture”. E3S Web of Conferences. Krynica, Poland. 6th International Conference - Renewable Energy Sources. Volume 154. 2020.

[8] Sheichenko V., Marynchenko I. and Dudnikov I., Eds. "Development of technology for the hemp stalks preparation". Independent Journal of Management and Production // State 
agrarian and engineering university in Podilia. - V. 10, № 7, p. 687 - 701 (ISSN: 2236-269X)

[9] Korchak M.M. "Development of a combined method and a grinder for soil littered by plant residues” Visnyk of Lvivsky national agrarian university: Agrarian and engineering research. № 13, volume 1. Lviv, 2009 pp.155 - 163.

[10] Korchak M.M. "Substantiation of the technological functional model of the method of tillage after harvesting rough-stem crops". Collection of scientific and research works. Podilsky Agrarian and Engineering University. Edition 24, part 2. Kamyanets-Podilsky, 2016. pp. 165 - 174.

[11] Korchak M., Dudchak T., Vilchinska D. "Theoretical substantiation of the working body for soil alignment”. Zhytomyr State Technological University. Series: Engineering, V. 1, 2019. pp. 69-75.

[12] Yermakov S., Mudryk K. and Hutsol T., Eds. "The analysis of stochastic processes in unloadingthe energywillow cuttings from the hopper”. Environment. Technology. Resources. Rezekne, Latvia. Proceedings of the 12th International Scientific and Practical Conference. Volume III. 2019. pp. 249-252, https://doi:10.17770/etr2019vol3.4159
[13] Ivanyshyn V., Yermakov S. and, Ishchenko T., Eds. "Calculation algorithm for the dynamic coefficient of vibro-viscosity and other properties of energy willow cuttings movement in terms of their unloading from the tanker". Proceedings of 6 th International Conference - Renewable Energy Sources, vol. 154, E3S Web of Conferences. $2020 . \quad$ pp. 04005. https://doi:10.1051/e3sconf/202015404005

[14] Tryhuba A., Hutsol T. and Glowacki S., Eds. "Forecasting Quantitative Risk Indicators of Investors in Projects of Biohydrogen Production from Agricultural Raw Materials". Processes 2021, 9, 258. https://doi.org/10.3390/pr9020258

[15] Tryhuba A, Hutsol T. and Tryhuba I, Eds. "Risk Assessment of Investments in Projects of Production of Raw Materials for $\begin{array}{llll}\text { Bioethanol”. } & \text { Processes. } & \text { 2021; } & \text { 9(1):12. }\end{array}$ https://doi.org/10.3390/pr9010012

[16] The way of releasing field from plant residues of rough-stem crops. Patent 90538, Ukraine, № a2008 04264; application 04.04.2008; published 11.05.2010, Bulletin № 9 .

[17] Combined grinder of plant residues of rough-stem crops. Patent 90535, Ukraine, № a2008 03070; application 11.03.2008; published 11.05.2010, Bulletin № 9 . 